\title{
Efeito da adição de adjuvantes à calda com fungicida em plantas de citros sob chuva artificial
}

\author{
Lucas Aparecido Gaion ${ }^{1}$, Olinto Lasmar ${ }^{2} \&$ Marcelo da Costa Ferreira ${ }^{2}$
}

\begin{abstract}
RESUMO
As aplicações de produtos fitossanitários a campo são passíveis de perdas pela ocorrência de chuvas, entretanto há aditivos à calda que propõem reduzir estas perdas, mantendo a retenção dos produtos nas superfícies tratadas. Assim, objetivou-se neste trabalho avaliar os efeitos da adição de adjuvantes à calda com oxicloreto de cobre aplicada em plantas de Citrus sinensis L. Osbeck sob a incidência de chuva artificial. Empregou-se o delineamento inteiramente ao acaso com quatro repetições para avaliar a tensão superficial, o ângulo de contato de gotas, o depósito e a retenção de calda em folhas de laranjeira antes e após a incidência de chuva artificial. Caldas fungicidas (oxicloreto de cobre, com adjuvantes: tributilcitrat + polimetilsiloxano; óleo vegetal; e copolímero de poliéter e silicone) foram aplicadas com pulverizador de pressão constante sobre mudas de laranjeira, até o ponto de escorrimento. Verificou-se que a adição dos adjuvantes proporcionou menor retenção de calda e não colaboraram para manter o depósito de calda após a ocorrência de chuva artificial. Além disso, a menor retenção obtida com o adjuvante copolímero de poliéter e silicone correlacionou-se positivamente aos menores valores de tensão superficial e ângulo de contato.
\end{abstract}

Termos de indexação: Citrus sinensis L. Osbeck, tecnologia de aplicação, pulverização.

\section{Effect of adjuvants to spray fungicide in citrus plants under artificial rain}

\section{SUMMARY}

Applications in the field of pesticides are subject to loss by rain, however there are additives to the spray solution which propose to reduce these losses, maintaining retention of products on the treated surfaces. Due that our aim was to evaluate the retention of pesticide spray with or without adjuvants in Citrus sinensis L. Osbeck considering incidence of artificial rain. We used fully randomized design with four replications to evaluate surface tension, deposit, and retention of fungicide spray on citrus leaves after and before artificial rain. Spray (copper oxychloride, with three adjuvants: tributilcitrat + polymethylsiloxane; vegetable oil and silicone polyether copolymer) in were applied on citrus seedlings to the point of run-off with a pressurized sprayer. It has been found that the addition of adjuvants resulted in lower retention and not helps maintaining deposit

\footnotetext{
${ }^{1}$ Faculdade de Ciências Agrárias e Veterinárias, Universidade Estadual Paulista - UNESP, Jaboticabal, SP, Brasil

2 Departamento de Fitossanidade, Faculdade de Ciências Agrárias e Veterinárias, Universidade Estadual Paulista - UNESP, Jaboticabal, SP, Brasil

Autor correspondente: Lucas Aparecido Gaion, Faculdade de Ciências Agrárias e Veterinárias, Universidade Estadual Paulista - UNESP, Via de Acesso Prof. Paulo Donato Castellane, s/n, Zona Rural, CEP 14884-900, Jaboticabal, SP, Brasil. E-mail: lucas.gaion@yahoo.com.br
} 
on citrus plants after the occurrence of artificial rain. Addiction of silicone polyether copolymer resulted in lower deposition on leaves before artificial rain. In addition, the lowest retention obtained by silicone adjuvant correlated positively to the surface tension and contact angles of droplets.

Index terms: Citrus sinensis L. Osbeck, application technology, spraying.

\section{INTRODUÇÃO}

As plantas cítricas são afetadas por inúmeras doenças, as quais requerem a aplicação de fungicidas cúpricos para seu controle ou prevenção. Dentre estas, merecem destaque, a mancha preta dos citros (MPC) (Phyllosticta citricarpa) e o cancro cítrico (Xanthomonas citri subsp. citri), esta última tem recebido maior atenção pela sua grande disseminação na última década, principalmente no estado de São Paulo (Behlau et al., 2016). Ambas as doenças se caracterizam pela formação de lesões na casca dos frutos, tornando-os menos atrativos ao consumo in natura e á exportação (Aguilar-Vildoso et al., 2002). Além disso, em condições favoráveis à doença como alta temperatura e umidade, pode ocorrer queda prematura dos frutos infectados, impactando negativamente a produção de frutos (Feichtenberger, 1996; Araújo et al., 2013).

O controle tanto da MPC quanto do cancro cítrico é realizado, principalmente, pelo emprego de caldas fungicidas, destacadamente fungicidas protetores à base de cobre acrescidos de adjuvantes, como óleo vegetal ou mineral, polímeros ou organosiliconados (Schutte et al., 2003; Orbovic et al., 2007; Hendricks et al., 2013). A adição de adjuvantes à calda de pulverização, de maneira geral, propõe a melhoria da eficiência de aplicação, através de alterações da tensão superficial, aderência e espalhamento da calda de pulverização na superfície tratada (Massinon \& Lebeau, 2013). Entretanto, deve-se sempre ter o cuidado de adequar o volume de aplicação, em função das profundas modificações químico-físicas promovidas pela adição de adjuvantes à calda (Berni et al., 1999; Ramos et al., 2007; Andrade et al., 2010; Iost \& Raetano, 2010; Massinon \& Lebeau, 2013). Por exemplo, há relatos de redução de até $75,5 \%$ da tensão superficial e de 100\% do ângulo de contato com adjuvantes organosiliconados (Mendonça et al., 1999; Iost \& Raetano, 2010).

Além disso, as aplicações de produtos fitossanitários a campo estão sujeitas a grandes perdas por deriva, evaporação, escorrimento da calda depositada nas superfícies tratadas, ou pela redução dos depósitos após a ocorrência de chuvas (Weber et al., 1937; Alvarenga et al., 2013; Ferreira et al., 2013). Contudo, um grande número de moléculas é destinado à redução de tais perdas quando adicionadas à calda de pulverização, colaborando com a retenção da calda na superfície tratada, mesmo sob a incidência de chuvas (Iost \& Raetano, 2010). Como agravante, no caso da aplicação de fungicidas cúpricos em citros que esta associada à ocorrência de doenças favorecidas por elevadas temperaturas e chuvas frequentes, é normal a perda de eficiência dos mesmos pela redução do depósito de cobre sobre as superfícies tratadas (Fonseca et al., 2016; Araújo et al., 2016). Chuvas de maior intensidade, que coincide, por exemplo, com a época de controle da mancha preta dos citros no estado de São Paulo, são normalmente mais eficientes em reduzir um depósito sobre a superfície foliar comparado a várias chuvas de mesmo volume e menor intensidade (Weber et al., 1937; Fonseca et al., 2016; Araújo et al., 2016). Por exemplo, Ocampo-Ruiz \& Matuo (1994) avaliando o efeito de diferentes adjuvantes verificaram que estes reduziram a tensão superficial e a retenção de calda, mas não impediram a remoção do produto após $10 \mathrm{~mm}$ de chuva artificial. Em contrapartida, verificou-se maior depósito de inseticida na cultura do amendoim após a incidência de chuva artificial de $20 \mathrm{~mm}$ quando utilizado o fertilizante nitrogenado (tributilcitrat+polidimetilsiloxano) adicionado à calda (Ferreira et al., 2013).

Desta forma, o objetivo deste trabalho foi avaliar o efeito da adição de adjuvantes à calda de pulverização sobre a tensão superficial, ângulo de contato, depósito e retenção de calda com fungicida cúprico em plantas de citros sob a incidência de chuva artificial.

\section{MATERIAL E MÉTODOS}

O experimento foi realizado em laboratório do Núcleo de Estudos e Desenvolvimento de Tecnologia de Aplicação - NEDTA do Departamento de Fitossanidade do Câmpus de Jaboticabal - SP, UNESP.

Foram avaliadas a tensão superficial e o ângulo de contato de gotas, retenção de calda e depósito de fungicida cúprico, sobre folhas de citros cultivar Valência. Os tratamentos foram constituídos por oxicloreto de cobre e as combinações com três adjuvantes (tributilcitrat + polimetilsiloxano; óleo vegetal; copolímero de poliéter e 
silicone) em concentrações recomendadas pelos fabricantes, e água utilizada como testemunha (Tabela 1).

Para as avaliações da tensão superficial e do ângulo de contato das gotas foi empregado o delineamento inteiramente casualizado em esquema fatorial $5 \times 3$ (caldas $\mathrm{x}$ tempo de avaliação) e $5 \times 2$ (caldas x superfície) para tensão superficial e ângulo de contato, respectivamente, com quatro repetições para cada tratamento.

As gotas foram formadas por uma microsseringa graduada com capacidade de $500 \mu \mathrm{L}$, dispensando-se volumes de $10 \mu \mathrm{L}$ para cada repetição. Durante o período de avaliações registrou-se temperatura de $25{ }^{\circ} \mathrm{C}$ e umidade relativa do ar de $65 \%$. A fim de avaliar o efeito dos adjuvantes no espalhamento das gotas as medições foram realizadas a cada segundo num tempo total de 180 segundos, em um tensiômetro automático modelo OCA 15 plus (Dataphysics Germany) no qual a tensão superficial é determinada pelo método da gota pendente. A imagem da gota é capturada por uma câmera acoplada ao equipamento, que analisa o formato da gota pendente por assimetria de eixos (ADSA - Axisymmetric Drop Shape Analysis). A tensão superficial é determinada por meio da digitalização e análise do perfil da gota, utilizando para ajuste a equação de Young-Laplace.

Para a avaliação da cinética do ângulo de contato de gotas, utilizou-se o mesmo equipamento (OCA 15 plus), que também obtém estes valores por análise de imagem. Para efeito de comparação do ângulo de contato das gotas, foram utilizadas duas superfícies com características diferentes. Uma das superfícies com menor afinidade à água (maior ângulo de contato da gota com a superfície), representada por folhas de citros da cultivar Valência. A outra superfície com maior afinidade à água (menor ângulo de contato da gota com a superfície), representada por uma lâmina de vidro. Assim como para a tensão superficial, as medições também ocorreram a cada segundo num tempo total de três minutos após a deposição de cada gota na superfície avaliada, indicando o progresso do espalhamento da gota sobre cada superfície.

Para a avaliação de retenção de calda sobre as folhas de citros utilizaram-se folhas totalmente desenvolvidas de mesmo fluxo vegetativo retiradas do terço médio da planta. Antes das avaliações estas foram lavadas e secas. Utilizou-se o delineamento inteiramente casualizado com cinco tratamentos (caldas de pulverização) e quatro repetições.

No momento da pulverização, cada folha foi posicionada verticalmente, pendurada pelo pecíolo ligado a uma haste apoiada em um suporte colocado sobre o prato de uma balança digital com precisão de um miligrama e dispostos dentro de uma bandeja de metal para receberem a pulverização. Neste momento a balança foi zerada (tara), para que imediatamente após cessar o escorrimento do excesso de calda, pudesse ser obtida apenas a massa do volume líquido que ficou retido sobre as folhas. Na sequência, procedeu-se à aplicação da calda de pulverização sobre as folhas, com o auxílio de um pulverizador pressurizado de modo a permitir que a calda atingisse uniformemente a superfície abaxial e adaxial de cada folha até o ponto de escorrimento. Foi considerada uma densidade igual a um ( massa $=$ volume $)$ para as caldas utilizadas.

Para determinar a área de cada uma das folhas utilizou-se um aparelho integrador de área foliar (LI-COR, modelo LI-3100C). Para a obtenção do valor de retenção de calda, o valor da massa retida em cada folha foi dividido pela área da respectiva folha $\left(\mu \mathrm{g} \mathrm{cm}^{-2}\right)$, considerando as superfícies adaxial e abaxial.

O depósito de fungicida (oxicloreto de cobre) foi avaliado em delineamento inteiramente ao acaso, no esquema fatorial $5 \times 2$, com quatro caldas (Tabela 1) e água como testemunha submetidas a duas condições: antes e após a incidência de chuva simulada, com quatro repetições, sendo que cada planta representou uma repetição.

As caldas foram pulverizadas sobre mudas de laranja da variedade Valência, com aproximadamente $80 \mathrm{~cm}$ de altura, em casa de vegetação, utilizando pulverizador costal pressurizado a $\mathrm{CO}_{2}$ com pressão de trabalho constante de $40 \mathrm{lbf} \mathrm{pol}^{-2}$. Utilizou-se o modelo de ponta de pulverização TXVK-18 $\left(\right.$ TeeJet $^{\circledR}$ ) com inserto de cerâmica e corpo de polipropileno, que produz gotas finas em um jato cônico vazio. No momento da aplicação a temperatura foi de $27,5^{\circ} \mathrm{C}$ e a umidade relativa do ar de $77 \%$. A aplicação

Tabela 1. Tratamentos utilizados para avaliação de aspectos da pulverização de cúprico em plantas cítricas

\begin{tabular}{lc}
\hline \multicolumn{1}{c}{ Tratamentos } & Dose (g ou mL p.c. $\left.100 \mathrm{~L}^{-1}\right)$ \\
\hline Oxicloreto de Cobre $*$ & $200 \mathrm{~g}$ \\
Oxicloreto de Cobre + tributilcitrat + polimetilsiloxano (1) & $200 \mathrm{~g}+10 \mathrm{~mL}$ \\
Oxicloreto de Cobre + óleo vegetal (2) & $200 \mathrm{~g}+500 \mathrm{~mL}$ \\
Oxicloreto de Cobre + copolímero de poliéter e silicone (3) & $200 \mathrm{~g}+75 \mathrm{~mL}$ \\
\hline
\end{tabular}

*Cuprogarb 500 PM; 1. Vertex Premium RS; 2. Veget'oil; 3. Silwet L-77 Ag. 
procedeu até o ponto de escorrimento caracterizando-a como de volume alto.

Cerca de uma hora e vinte minutos após a pulverização, quando as mudas ficaram secas, foram coletadas duas folhas por planta para quantificação do íon metálico de cobre contido no fungicida, antes da chuva artificial. Em seguida simulou uma chuva com uma lâmina d'água de $20 \mathrm{~mm}$, por período de 10 minutos. Utilizou-se um aspersor estacionário equipado com seis pontas de pulverização modelo FL10 $\left(\right.$ TeeJet $^{\circledR}$ ) de aço inoxidável, que produz gotas grossas em jato cônico cheio de grande ângulo, permitindo até $100 \mathrm{~cm}$ de diâmetro da área com chuva. Com as plantas secas novamente, foram coletadas duas folhas por planta para avaliar o depósito do íon metálico após a chuva.

As folhas coletadas foram acondicionadas em sacos de plástico e levadas ao laboratório onde ficaram imersas em solução de ácido clorídrico a $0,2 \mathrm{~N}$ e mantidas em repouso por 60 minutos. Os extratos foram filtrados e a concentração do íon de cobre metálico foi quantificada por espectrofotometria de absorção atômica (Thermo iCE 3000). As quantidades obtidas do íon foram correlacionadas com a área foliar correspondente para determinar o depósito de íon metálico $\left(\mathrm{em} \mu \mathrm{g} \mathrm{Cu}{ }^{2+} \mathrm{cm}^{-2}\right.$ de folha). Para determinar a área de cada uma das folhas, estas foram medidas em um aparelho integrador de área foliar (LI-COR, modelo LI-3100C).

Os dados foram submetidos à análise de variância pelo teste $\mathrm{F}$ e as médias comparadas pelo teste de Tukey $(\mathrm{p}<0,05)$.

\section{RESULTADOS E DISCUSSÃO}

A adição de adjuvantes á calda de pulverização reduziu a tensão superficial independente do adjuvante utilizado (Figura 1). Contudo, a combinação de oxicloreto de cobre com o copolímero de poliéter e silicone resultou nas menores tensões superficiais, seguida da calda com óleo vegetal e tributilcitrat + polimetilsiloxano (Figura 1). Além disso, o oxicloreto de cobre sem adjuvante na calda não alterou significativamente a tensão superficial, em relação à testemunha (água). Por outro lado, observou-se que há redução da tensão superficial do líquido ao longo do tempo de avaliação em todos os tratamentos, exceto para testemunha (água) (Figura 1). Resultados semelhantes foram verificados por Mendonça et al. (1999) que avaliaram adjuvantes organosiliconados combinados a glyphosate e verificaram que o copolímero de poliéter e silicone foi o que mais reduziu a tensão superficial da calda. Da mesma maneira, a adição de óleo mineral ou vegetal à água reduziu significativamente a tensão superficial da calda, embora as modificações tenham dependido não apenas da origem do óleo, mas também da sua concentração na calda de pulverização, uma vez que o aumento da concentração do óleo na calda até $1 \%$ causou reduções mais expressivas de tensão superficial (Mendonça et al., 2007). Estas discussões são compatíveis com os resultados verificados nos experimentos deste trabalho.

Quanto ao espalhamento das gotas, verificou-se redução do ângulo de contato em todos os tratamentos ao longo do período de avaliação. Ao início da avaliação (1 segundo) os maiores ângulos de contato foram produzidos pelos

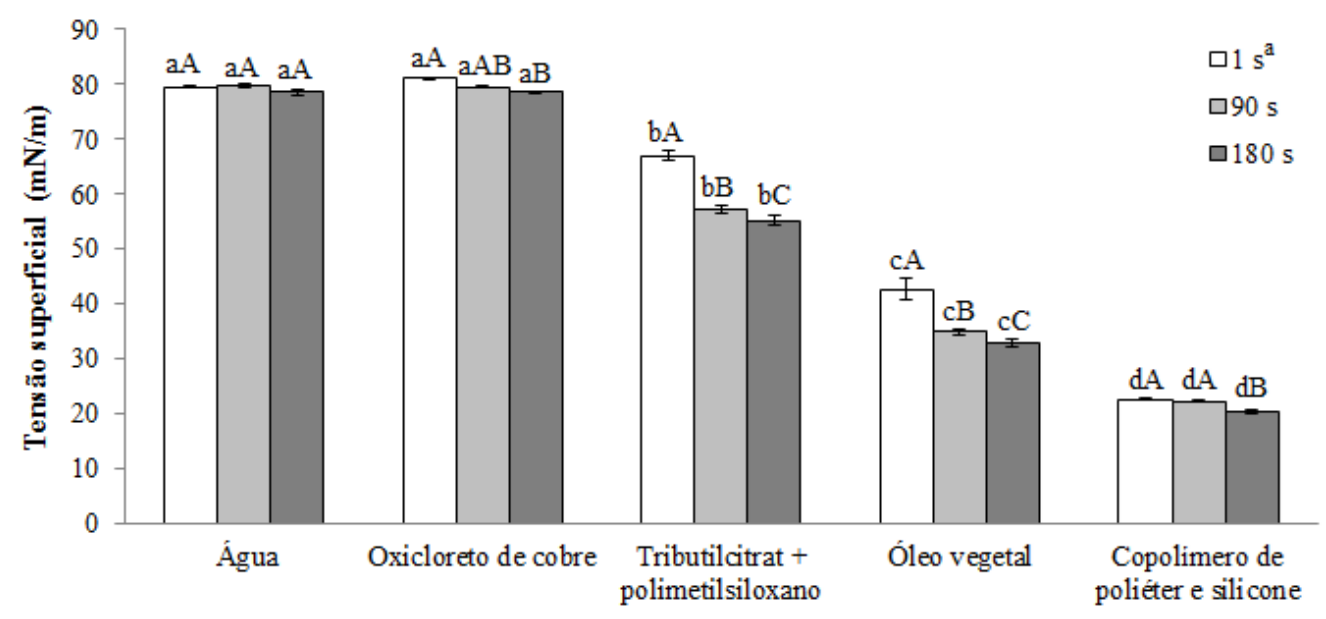

Figura 1. Tensão superficial das gotas em função da adição de adjuvantes à calda de pulverização. ${ }^{a}$ Tempo decorrido a partir do início da avaliação. Médias seguidas pela mesma letra minúscula entre tratamentos e maiúsculas entre os tempos não diferem entre si pelo teste de Tukey a 5\% de probabilidade. 
tratamentos com água e óxicloreto de cobre (Tabela 2). Similarmente, decorrido 90 segundos de avaliação as gotas compostas por oxicloreto de cobre apresentaram maior ângulo de contato diferindo estatisticamente das gotas formadas a partir da calda de oxicloreto de cobre e óleo vegetal. Enquanto que aos 180 segundos de avaliação as gotas de água apresentaram maior ângulo de contato não diferindo das gotas das caldas de oxicloreto de cobre e oxicloreto de cobre com tributilcitrat + polimetilsiloxano, ambos com ângulos maiores ao das gotas das caldas de oxicloreto de cobre e óleo vegetal, este último apresentou os menores ângulos de contato ao término do período de avaliação (Tabela 2). Com relação à superfície, o ângulo de contato foi maior (menor espalhamento) sobre a superfície vegetal, em todas as avaliações. Não houve interação significativa entre os fatores avaliados (Tabela 2).

Curiosamente não foi possível avaliar o ângulo de contato das gotas compostas de oxicloreto de cobre e copolímero de poliéter e silicone, uma vez que o espalhamento ocorria de maneira rápida, ultrapassando o campo de visão da câmera e impossibilitando a captura da imagem. Como será discutido a seguir o maior espalhamento das gotas sobre as superfícies, principalmente sobre o vidro, se correlaciona positivamente com a baixa tensão superficial das mesmas (Figura 2). De fato, as gotas formadas a partir da calda de oxicloreto de cobre e copolímero de poliéter e silicone apresentam a menor tensão superficial em comparação com os demais tratamentos (Figura 1). Dessa forma, foi calculado o coeficiente de Pearson $(p)$ que indicou haver forte correlação positiva entre o ângulo de contato das gotas após 180 segundos sobre a superfície hidrofílica (vidro) e a tensão superficial (Figura 2). Portanto, a tensão superficial influencia diretamente a capacidade de espalhamento das gotas, sendo que quanto menor a tensão superficial do líquido, menor o ângulo de contato e maior é o espalhamento das gotas. Isto resulta da adição de tenso-ativos que promovem rearranjos moleculares de maneira que a extremidade polar das moléculas situa-se voltada para a água, enquanto a outra extremidade voltada para a interface em que o líquido está em contato, "quebrando" assim a tensão superficial da calda e por consequência reduzindo o ângulo de contato em relação à folha e aumentando a molhabilidade (Iost \& Raetano, 2010).

Além disso, com a redução tanto da tensão superficial quanto do ângulo de contato das gotas em função da adição de adjuvantes, o espalhamento da calda é favorecido proporcionando maior área de cobertura, aumentando a possibilidade de que a calda entre em contato com alvo desejado. Da mesma forma, o maior espalhamento aumenta a possibilidade de absorção do produto. Isso justifica a importância do emprego de adjuvantes nas aplicações em volumes reduzidos. No entanto, algumas características podem ser discutidas, uma vez que a

Tabela 2. Ângulo de contato das caldas fitossanitárias ao 1, 90 e 180 segundos em superfície de vidro e folha de citros

\begin{tabular}{|c|c|c|c|}
\hline \multirow{3}{*}{ Tratamentos } & \multicolumn{3}{|c|}{ Tempo (segundos) } \\
\hline & 1 & 90 & 180 \\
\hline & \multicolumn{3}{|c|}{ Ângulo de contato $\left(\theta^{\circ}\right)$} \\
\hline \multicolumn{4}{|l|}{ Caldas (A) } \\
\hline Água & $58,38 \mathrm{~A}$ & $44,75 \mathrm{AB}$ & $46,40 \mathrm{~A}$ \\
\hline Oxicloreto de cobre & $58,78 \mathrm{~A}$ & $49,32 \mathrm{~A}$ & $40,60 \mathrm{~A}$ \\
\hline Oxicloreto de cobre + tributilcitrat + polimetilsiloxano & $50,41 \mathrm{~B}$ & $42,84 \mathrm{AB}$ & $37,92 \mathrm{AB}$ \\
\hline Oxicloreto de cobre + óleo vegetal & $46,16 \mathrm{~B}$ & $34,44 \mathrm{~B}$ & $28,91 \mathrm{~B}$ \\
\hline Teste F & $23,66 * *$ & $4,30 *$ & $6,11 * *$ \\
\hline \multicolumn{4}{|l|}{ Superfície (B) } \\
\hline Artificial (vidro) & $23,03 \mathrm{~B}$ & $18,19 \mathrm{~B}$ & $13,31 \mathrm{~B}$ \\
\hline Vegetal (folha de laranja) & $75,96 \mathrm{~A}$ & $67,48 \mathrm{~A}$ & $63,61 \mathrm{~A}$ \\
\hline Teste F & $417,40 * *$ & $270,01 * *$ & $291,56^{* *}$ \\
\hline \multicolumn{4}{|l|}{ Interação } \\
\hline $\mathrm{AxB}$ & $1,19^{\mathrm{NS}}$ & $1,41^{\mathrm{NS}}$ & $1,39^{\mathrm{NS}}$ \\
\hline $\mathrm{CV}(\%)$ & 14,80 & 19,80 & 21,66 \\
\hline DMS (5\%) & 10,1036 & 11,6968 & 11,4875 \\
\hline
\end{tabular}

*: significativo $(\mathrm{P}<0,05)$;**: significativo $(\mathrm{P}<0,01)$; NS: não significativo; Média seguidas de mesma letra maiúscula na coluna não diferem entre si pelo teste de Tukey a $5 \%$ de probabilidade. 
adição de adjuvantes ao mesmo tempo em que melhora a capacidade de espalhamento das gotas, reduz a capacidade de retenção de calda nas folhas, podendo causar maior escorrimento e consequentemente menor retenção do ingrediente ativo sobre o alvo. Por exemplo, OcampoRuiz \& Matuo (1994) relataram que a necessidade de espalhantes-adesivos é questionável em aplicações em volume alto, pois as gotas individualizadas coalescem e formam glóbulos maiores que posteriormente escorrem da superfície da folha. A rigor, isto implica na eficiência da operação e requer ajuste adequado do volume de aplicação (Scapin et al., 2015; Silva Junior et al., 2016)

O ângulo de contato das gotas é influenciado pela tensão superficial da solução e pela afinidade das substâncias componentes desta com os constituintes da superfície onde estão depositadas. Por exemplo, a quantidade de cera da cutícula interfere diretamente no comportamento das gotas depositadas na superfície foliar (Albert \& Victoria Filho, 2002). Desta forma, o comportamento de uma gota em uma determinada superfície depende da interação entre superfície e líquido, sendo que um mesmo líquido pode se espalhar de maneira diferente em superfícies distintas (Moita Neto, 2006). Por exemplo, Iost \& Raetano (2010) avaliaram diferentes adjuvantes e sua influência sobre a tensão superficial e o ângulo de contato das gotas em superfícies artificiais e naturais. De maneira geral, há maior espalhamento das gotas na superfície artificial (vidro) em comparação com superfícies vegetais, e os adjuvantes organosiliconados como o copolímero de poliéter e silicone foram mais eficientes em reduzir a tensão superficial e aumentar o espalhamento das gotas.

De fato, quando avaliada a retenção de calda, embora não tenha sido verificada diferença entre a testemunha (água) e oxicloreto de cobre sem adjuvantes, a adição de adjuvantes claramente reduziu a retenção de calda em folhas de laranjeira. Destacadamente, o emprego de copolímero de poliéter e silicone reduziu fortemente a retenção de calda (Figura 3).

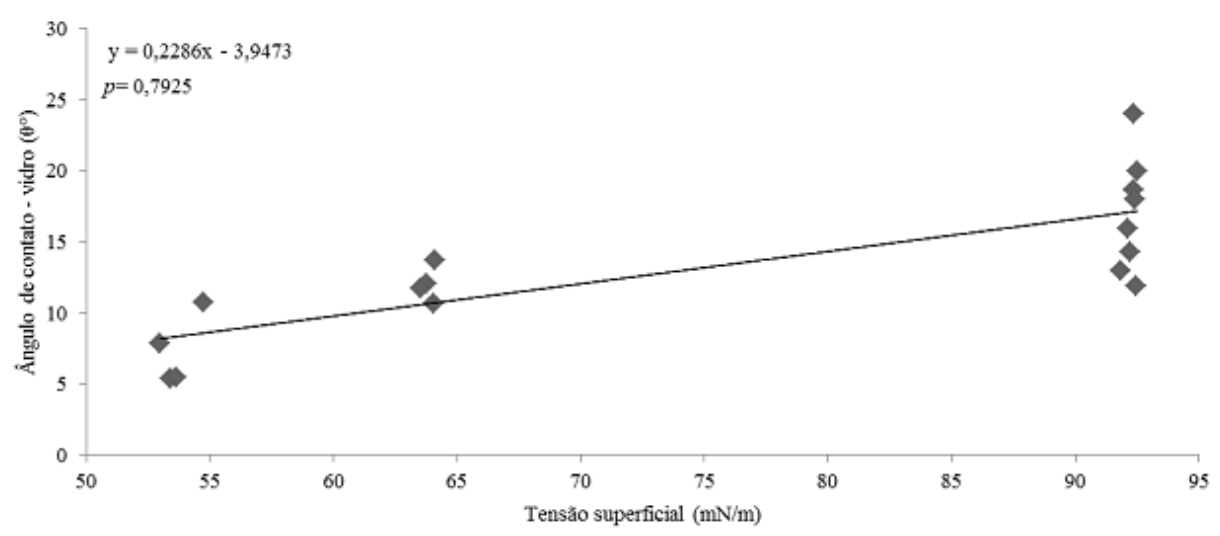

Figura 2. Correlação entre ângulo de contato sobre a superfície de vidro após 180 segundos e a tensão superficial.

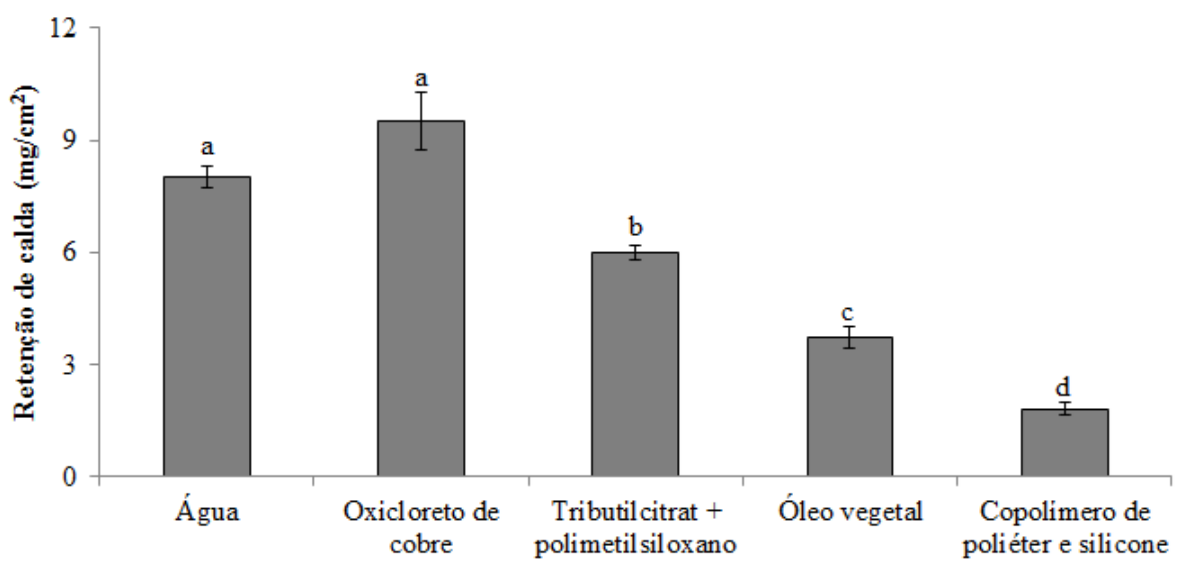

Figura 3. Retenção de calda cúprica sobre folhas de citros em função da adição de adjuvantes. Médias seguidas da mesma letra não diferem entre si pelo teste de Tukey a 5\% de probabilidade. 
A.

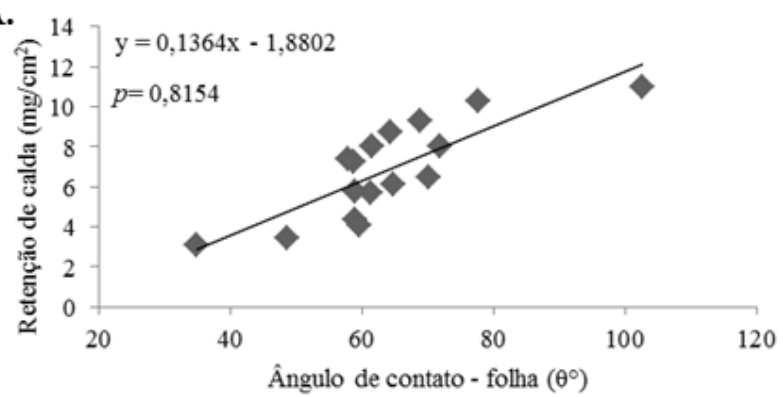

B.
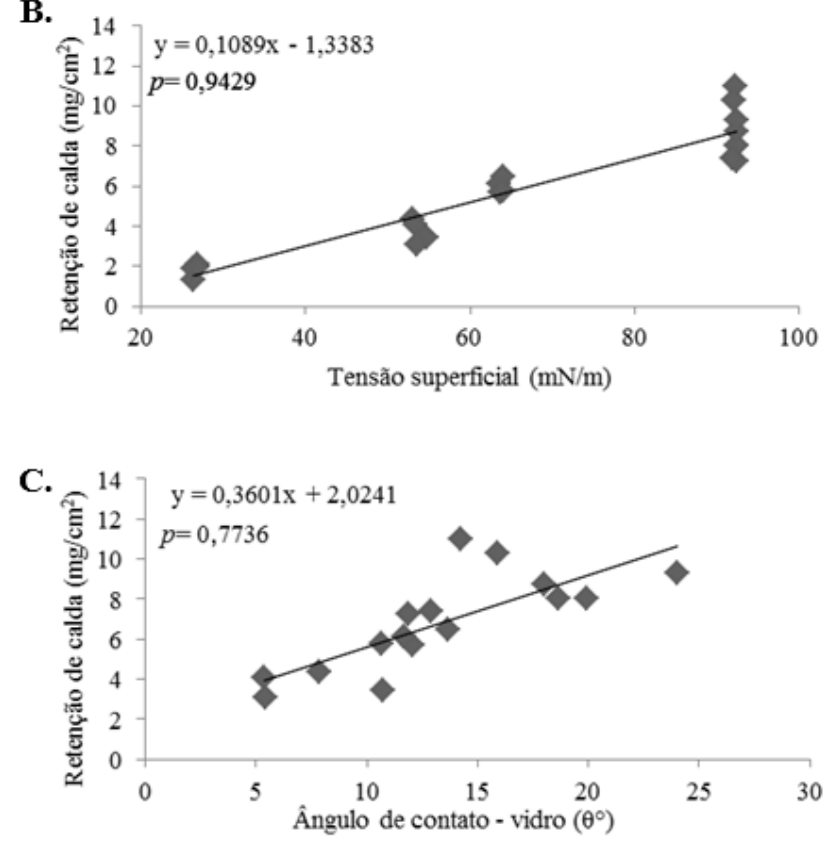

Figura 4. Retenção de calda à base de água, oxicloreto de cobre, tributilcitrat, óleo vegetal e copolímero de poliéter e silicone em função da tensão superficial (A), ângulo de contato das gotas sobre as folhas cítricas (B) e ângulo de contato das gotas sobre a superfície de vidro (C).
Além disso, a retenção de caldas em folhas de citros apresentou uma forte correlação positiva com a tensão superficial das gotas, com o ângulo de contato das gotas na folha cítrica e com menor significância para a superfície de vidro (Figura 4). Ambos os fatores, tensão superficial e ângulo de contato das gotas, estão relacionados com a capacidade de espalhamento das gotas (Figuras 1 e 2), e a redução dessas variáveis acarreta em menor retenção de calda em função do maior escorrimento de calda fungicida.

Similarmente, a adição de óleo mineral ou vegetal ao acaricida cyhexatin causou redução da retenção da calda de pulverização em folhas de citros em aplicações de volume alto em função do maior espalhamento das gotas (Andrade et al., 2010). De fato, o uso de adjuvantes pode ser prejudicial em aplicações que causam escorrimento, uma vez que diminui consideravelmente a capacidade de retenção de calda pelas folhas. Por outro lado, a adição de adjuvantes às caldas, sobretudo os tenso-ativos, permite a obtenção de uma mesma cobertura do alvo com volumes de aplicação consideravelmente menores, devendo-se levar em conta e compreender a influência desta redução no resultado de depósito do produto comercial (Bueno et al., 2013). Se bem empregados, os adjuvantes podem possibilitar a redução do volume a ser aplicado, com ganhos na capacidade operacional, e manter a cobertura e a eficiência do produto aplicado por aumentar a área de contato com a folha através do maior espalhamento das gotas (Ferreira et al., 2010).

Com relação ao depósito de cobre nas folhas de citros, os maiores valores foram obtidos quando se utilizou o oxicloreto de cobre isoladamente, entretanto, este por sua vez, não diferiu dos tratamentos com tributilcitrat + polimetilsiloxano ou óleo vegetal (Tabela 3). Esses resultados corroboram com o verificado quanto ao maior espalhamento da gota em função da adição do adjuvante

Tabela 3. Depósito de íon metálico em folhas de citros em função do uso de adjuvantes.

\begin{tabular}{lrrrrr}
\hline \multicolumn{1}{c}{ Tratamentos } & \multicolumn{3}{c}{ Depósito $\mathrm{Cu}^{2+}\left(\mu \mathrm{g} \mathrm{cm}^{-2}\right)$} & \multicolumn{2}{c}{$\begin{array}{c}\text { Redução após a } \\
\text { chuva }(\%)\end{array}$} \\
\cline { 2 - 4 } & \multicolumn{2}{c}{ Antes da chuva } & Após a chuva & \\
Testemunha & 0,06 & $\mathrm{cA}$ & 0,03 & $\mathrm{cA}$ & 50,00 \\
Oxicloreto de cobre $(\mathrm{Cu})$ & 18,61 & $\mathrm{aA}$ & 6,98 & $\mathrm{aB}$ & 62,49 \\
Oxicloreto de $\mathrm{Cu}+$ tributilcitrat + polimetilsiloxano & 13,02 & $\mathrm{abA}$ & 6,14 & $\mathrm{abB}$ & 52,84 \\
Oxicloreto de $\mathrm{Cu}+$ óleo vegetal & 12,64 & $\mathrm{abA}$ & 5,79 & $\mathrm{abB}$ & 54,19 \\
Oxicloreto de $\mathrm{Cu}+$ copolímero de poliéter e silicone & 10,98 & $\mathrm{bA}$ & 4,50 & $\mathrm{abB}$ & 59,01 \\
Média & 11,06 & & 4,69 & & 55,70 \\
$\mathrm{CV}(\%)$ & & 39,71 & & & 31,78 \\
\hline
\end{tabular}

Média seguidas de mesma letra minúscula na coluna e maiúscula na linha não diferem entre si pelo teste de Tukey a $5 \%$ de probabilidade. 
de copolímero de poliéter e silicone à calda, resultando na formação de uma camada de calda mais delgada sobre a folha, resultante do maior escorrimento na aplicação em volume alto, e consequentemente em menor depósito do fungicida sobre a superfície das plantas.

Após a incidência da chuva artificial sobre as mudas de laranja pode-se observar uma forte redução do depósito de cobre sobre as folhas, independente do uso ou não de adjuvantes, por outro lado, como esperado a testemunha (água) não apresentou valores significativos de cobre depositado sobre as folhas, antes ou após a chuva (Tabela 3). Considerando a proporção de calda depositada e a retirada, verifica-se que a calda do fungicida sem adjuvante apresentou redução maior que $62 \%$ da calda inicialmente depositada, enquanto as caldas com tributilcitrat + polimetilsiloxano sofreu redução em torno de $53 \%$. Assim, nenhum dos adjuvantes evitou as perdas de depósito sobre as mudas quando submetidas a uma chuva artificial de $20 \mathrm{~mm}$ (Tabela 3 ).

\section{CONCLUSÕES}

Com base nos resultados observados, podemos concluir que todos os adjuvantes avaliados são eficientes em reduzir a tensão superficial e o ângulo de contato da calda com fungicida cúprico, assim favorecendo o maior espalhamento da calda sobre a superfície tratada, e dentre estes o copolímero de poliéter e silicone proporcionou o maior espalhamento das gotas. No entanto, quando empregados juntamente com aplicações em alto volume, os mesmos reduzem a retenção de calda e o depósito de cobre podendo comprometer a eficácia do controle. Evidenciando a necessidade de realização de trabalhos para ajuste do volume de aplicação quando da adição de adjuvantes a calda de pulverização. Além disso, nenhum dos adjuvantes foi capaz de reduzir as perdas do íon cobre após a incidência de precipitação.

\section{REFERÊNCIAS}

Aguilar-Vildoso CI, Ribeiro JGB, Feichtenberger E, Goes A \& Spósito MB (2002) Manual técnico de procedimentos da mancha-preta dos citros. Brasília: MAPA/DAS/ DDIV. $72 \mathrm{p}$.

Albert LHB \& Victoria Filho R (2002) Características morfológicas da cutícula foliar e efeitos de adjuvantes no controle químico de três espécies de guanxumas. Ciência e Agrotecnologia 26: 888-899.

Alvarenga CB, Teixeira MM, Zolnier S, Sasaki RS \& Rinaldi PCN (2013) Controle automático do espectro de gotas de pulverizador hidropneumático em função do déficit de pressão de vapor d'água no ar. Pesquisa Agropecuária Tropical 43: 26-33.

Andrade DJ, Ferreira MC \& Santos NC (2010) Efeito da adição de óleos ao acaricida cyhexatin sobre o ácaro Brevipalpus phoenicis e na retenção de calda por folhas de citros. Revista Brasileira de Fruticultura 32(4): 1055-1063.

Araújo D, Raetano CG, Ramos HH, Rocha DSR, Prado EV \& Aguiar VC (2016) Interference of spray volume, fruit growth and rainfall on spray deposits in citrus black spot control periods. Ciência Rural 46(5): 825-831.

Araújo D, Raetano CG, Ramos HH, Spósito MB \& Prado EV (2013) Interference of spray volume reduction in citrus black spot (Guignardia citricarpa Kiely) control in Valencia citrus fruits. Summa Phytopathologica 39(3): 172-179.

Behlau F, Fonseca AE \& Belasque J Junior (2016) A comprehensive analysis of the Asiatic citrus canker eradication programme in São Paulo state, Brazil, from 1999 to 2009. Plant Pathology 65: 1390-1399.

Berni RF, Machado VOF, Costa GR, Barata G \& Paula RS (1999) Avaliação da cobertura de gotas provocada por diferentes bicos de pulverização na cultura do milho e do feijão. Pesquisa Agropecuária Tropical 29(1): 49-52.

Bueno MR, Alves GJ, Paula ADM \& Cunha JPAR (2013) Volumes de calda e adjuvante no controle de plantas daninhas com glyphosate. Planta Daninha 31(3): 705-713.

Feichtenberger E (1996) Mancha-preta dos citros no Estado de São Paulo. Laranja 17: 93-108.

Ferreira MC, Alandia RA, Carvalho GFG \& Baggio MV (2010) Determinação de área foliar e retenção de líquido por folhas de café em pulverização a alto volume. Nucleus 7(1): $277-283$.

Ferreira MC, Lasmar O, Decaro ST Junior, Neves SS \& Azevedo LH (2013) Qualidade da aplicação de inseticida em amendoim (Arachis hypogaea L.), com e sem adjuvantes na calda, sob chuva simulada. Bioscience Journal 29: 1431-1440.

Fonseca AE, Nunes BM \& Ferreira Júnior LB (2016) Tenacity and persistence of copper fungicides in citrus 
seedlings under simulated rainfall. Revista Caatinga 29(3): 677-684.

Hendricks M, Katherine E, Donahoo RS, Roberts PD \& Christman MC (2013) Effect of copper on growth characteristics and disease control of the recently introduced Guignardia citricarpa on citrus in Florida. American Journal of Plant Sciences 4(2): 282-290.

Iost CAR \& Raetano CG (2010) Tensão superficial dinâmica e ângulo de contato de soluções aquosas com surfactantes em superfícies artificiais e naturais. Engenharia Agrícola 30(4): 670-680.

Massinon M \& Lebeau F (2013) Review of physicochemical processes involved in agrochemical spray retention. Biotechnologie, Agronomie, Société et Environnement 17(3): 494-504.

Mendonça CG, Raetano CG \& Mendonça CG (2007) Tensão superficial estática de soluções aquosas com óleos minerais e vegetais utilizados na agricultura. Engenharia Agrícola 27: 16-23.

Mendonça CG, Velini ED, Martins D \& Mendonça CG (1999) Efeitos de adjuvantes sobre a tensão superficial e a área de molhamento de soluções de glyphosate sobre folhas de tiririca. Planta Daninha 17(3): 355-365.

Moita Neto JM (2006) Molhamento e ângulo de contato. Teresina: Fundação de Amparo a Pesquisa do Estado do Piauí. Disponível em: <http://www.fapepi.pi.gov.br/ ciencia/documentos/Molhamento. PDF>. Acesso em: 29 fev. 2012.

Ocampo-Ruiz RA \& Matuo T (1994) Efeito de espalhantes adesivos na retenção e na ação do propargite sobre
Brevipalpus phoenicis (Geys) em folhas de citros. Anais da Sociedade Entomológica do Brasil 23: 265-270.

Orbovic V, Achor D \& Syvertsen JP (2007) Adjuvants affect penetration of copper through isolated cuticles of Citrus leaves and fruit. HortScience 42(6): 1405-1408.

Ramos HH, Yanai K, Corrêa IM, Bassanezi RB \& Garcia LC (2007) Características da pulverização em citros em função do volume de calda aplicado com turbopulverizador. Engenharia Agrícola 27: 56-65.

Scapin MS, Behlau F, Scandelai LHM, Fernandes RS, Silva GJ Junior \& Ramos HH (2015) Tree-row-volumebased sprays of copper bactericide for control of citrus canker. Crop Protection (Guildford, Surrey) 77: 119-126.

Schutte GC, Mansfield RI, Smith H \& Beeton KV (2003) Application of azoxystrobin for control of benomylresistant Guignardia citricarpa on 'Valencia' oranges in South Africa. Plant Disease 87: 784-788.

Silva Junior GJ, Scapin MDS, Silva FP, Silva ARP, Behlau F \& Ramos HH (2016) Spray volume and fungicide rates for citrus black spot control based on tree canopy volume. Crop Protection (Guildford, Surrey) 85: 38-45.

Weber AL, Mclean HC, Driggers BF \& Oneil WJ (1937) Influence of different materials on coverage and adhesiveness of sprays and their effect on residue removal from apples. New Jersey Agricultural Experimental Station Bulletin 627: 1-16.
Recebido: Agosto 25, 2015 Aceito: Julho 04, 2017 